\title{
OS PRINCÍPIOS GERAIS DO DIREITO AMBIENTAL
}

Fúlvia Leticia Perego Silva; Munir Jorge Felício

Universidade do Oeste Paulista-UNOESTE, Mestrado em Meio Ambiente e Desenvolvimento Regional - MMADRE, Presidente Prudente/SP. E-mail: fulvialeticia.adv@uol.com.br.

\section{RESUMO}

Ao consagrar o meio ambiente como um direito humano fundamental, a Constituição Federal de 1988, consagrou também de forma explícita e implícita os mais relevantes princípios do Direito Ambiental. Assim, os princípios são utilizados como fundamento ou alicerce do Direito e se encontram hierarquicamente superiores a qualquer regra. Dessa forma, o presente trabalho de pesquisa tem por objetivo verificar os principais princípios ambientais e sua importância para o ordenamento jurídico ambiental. Utilizou-se como metodologia a pesquisa eminentemente bibliográfica e exploratória. Conclui-se que para a concretização da efetiva proteção ambiental é de suma importância que os princípios basilares que fundamentam o Direito Ambiental sejam respeitados, integralizados e harmonizados ao sistema jurídico vigente, para que se busque o verdadeiro alcance da norma jurídica em prol de um direito ao meio ambiente ecologicamente equilibrado, garantindo-se a preservação das presentes e futuras gerações.

Palavras-chave: Princípios. Direito Ambiental. Alcance. Meio Ambiente. Norma Jurídica.

\section{THE GENERAL PRINCIPLES OF ENVIRONMENTAL LAW}

\begin{abstract}
By devoting the environment as a fundamental human right, the Federal Constitution of 1988, also devoted explicitly and implicitly the most important principles of environmental law. Thus, the principles are used as the basis or foundation of Law and are hierarchically superior to any rule. Thus, the present research aims to determine the main environmental principles and their importance to the environmental law. It was used as a methodology eminently bibliographic and exploratory research. We conclude that for the achievement of effective environmental protection is of paramount importance that the basic principles underlying the environmental law are respected, paid up and harmonized the existing legal system, in order to seek the true scope of the legal rule in favor of a right to an ecologically balanced environment, ensuring the preservation of present and future generations.
\end{abstract}

Keywords: Principles. Environmental Law. Range. Environment. Legal Standard. 


\section{INTRODUÇÃO}

Ao longo do século $X X$ a ruptura entre a natureza e o ser humano chegou às últimas consequências, tendo o meio ambiente se tornado um interesse internacional e uma preocupação de cada Estado. Por conseguinte, houve a positivação do direito fundamental ao meio ambiente ecologicamente equilibrado na Constituição Federal de 1988, fazendo surgir, a partir de então, um complexo de direitos e deveres, dentre eles o direito ao ambiente sadio e o dever de proteger os bens ambientais (TEIXEIRA, 2006).

O constituinte brasileiro dedicou um capítulo inteiro ao meio ambiente, estabelecendo no caput do artigo 225 da Constituição Federal que "todos têm direito ao meio ambiente ecologicamente equilibrado, bem de uso comum do povo e essencial à sadia qualidade de vida, impondo-se ao Poder Público e à coletividade o dever de defendê-lo e preservá-lo para as presentes e futuras gerações". Nesse sentido, "a realização plena do direito à vida, à saúde e à segurança pressupõe a implementação do direito ao meio ambiente ecologicamente equilibrado" (MILARÉ, 2014, p. 130).

Dentre os direitos de terceira geração, o direito ao meio ambiente ecologicamente equilibrado se destaca como o mais elaborado, pois é um direito assegurado à pessoa humana e é garantido pelo poder público como fundamental, sobrepondo-se, inclusive, aos direitos de natureza privada (FERREIRA FILHO, 2011). Consubstancia-se como sendo um direito de 'todos', por extrapolar o âmbito particular, individual.

Sendo assim, defende-se que os direitos fundamentais são assegurados em normas jurídicas com conteúdo essencial relativo, baseado em princípio. Ressalta-se que as normas jurídicas podem ser diferenciadas em regras e princípios, tendo como conteúdo os valores com força vinculante e validade positiva. Os princípios têm valor normativo, valorativo, interpretativo ou argumentativo e desempenham as funções de interpretação das normas legais, de integração e harmonização do sistema jurídico, bem como aplicação ao caso concreto.

Dessa forma, o presente trabalho de pesquisa tem por objetivo verificar os principais princípios ambientais e sua importância para o Direito Ambiental, contribuindo para uma reflexão acerca da necessidade da efetiva aplicação dos princípios que norteiam as normas ambientais para que se busque o verdadeiro alcance da norma jurídica ambiental em prol de um direito ao meio ambiente ecologicamente equilibrado, a preservar as presentes e futuras gerações.

\section{METODOLOGIA}

Utilizou-se como metodologia a pesquisa eminentemente bibliográfica e exploratória, possibilitando a compreensão e importância dos principais princípios do Direito Ambiental, para que o alcance pretendido pela norma jurídica ambiental seja alcançado, ou seja, a efetiva a proteção do meio ambiente.

\section{DISCUSSÃO}

O Direito Ambiental é um dos mais recentes setores do Direito moderno. Seu surgimento, como disciplina jurídica, denota que as relações entre o ser humano e o mundo que o envolve vêm se modificando de forma muito acelerada e profunda. Dessa forma, Machado (2014, p. 58-59) afirma:

Não se trata mais de construir um Direito das águas, um Direito da atmosfera, um Direito do solo, um Direito florestal, um Direito da fauna ou um Direito da biodiversidade. O Direito Ambiental não ignora o que cada matéria tem de específico, mas busca interligar estes temas com a argamassa da identidade dos instrumentos jurídicos de prevenção e de reparação, de informação, de monitoramento e de participação. 
Para Antunes (2015, p. 6) o Direito Ambiental é, portanto, "a norma que, baseada no fato ambiental e no valor ético ambiental, estabelece mecanismos aptos a disciplinar as atividades humanas em relação ao meio ambiente". Assim, referida disciplina deverá buscar respostas para solucionar ou minimizar os problemas ambientais que estão emergindo, fazendo sempre a articulação da legislação, da doutrina e da jurisprudência concernentes aos elementos que integram o meio ambiente, procurando evitar o isolamento dos temas ambientais e sua abordagem antagônica.

A produção da norma ambiental é dotada de uma complexidade específica. Desse modo, os princípios do Direito Ambiental tornam-se mais relevantes, pois "é a partir deles que as matérias que ainda não foram objeto de legislação específica podem ser tratadas pelo Poder Judiciário e pelos aplicadores do Direito, pois, na inexistência de norma legal, há que se recorrer aos diferentes elementos formadores do Direito" (ANTUNES, 2015, p. 22).

'Princípio', de modo geral, é "utilizado como alicerce ou fundamento do Direito" (MACHADO, 2014, p. 61). A análise dos princípios gerais que norteiam qualquer sistema jurídico, de qualquer ramo do Direito, tem, portanto, uma indiscutível relevância prática, pois permite a visualização global do sistema para a melhor aplicação das normas no mundo real dos fatos, tornando-as mais concretas possíveis. Assim:

Os princípios gerais são precisamente de direito porque integram o ordenamento jurídico de uma nação, sendo competência da doutrina e da jurisprudência descobri-los e aplica-los, através da legislação, ou então pelo sentimento de justiça e pela equidade, o que permite até o afastamento da legislação. Tanto é assim que, em nome dos mesmos princípios gerais, admitem-se decisões contra legem, caso em que os princípios em que se apoiam servirão para corrigir o direito positivo ou até para transformá-lo (COELHO, 2011, p. 65, grifo do autor).

Sendo assim, "os princípios têm valor normativo, e não apenas valorativo, interpretativo ou argumentativo, de maneira que se encontram hierarquicamente superiores a qualquer regra" (FARIAS, 2006). Dessa forma, os princípios norteiam o ordenamento jurídico, devendo as regras a eles se adequar e não o contrário, o que poderá acarretar a sua nulidade. Nesse contexto:

Os princípios, cuja função sistematizadora do ordenamento jurídico é evidente, têm primazia formal e material sobre as regras jurídicas, impondo padrões e limites à ordem jurídica vigente. Importante destacar ainda sua função normogenética na medida em que atuam na elaboração das regras jurídicas. Perante eventuais antagonismos existentes entre valores constitucionais, deve-se fazer o juízo de adequação de princípios e a ponderação de valores (GARCIA; THOMÉ, 2015, p. 17).

Destaca Belchior (2011, p. 90) que "os princípios jurídicos no atual contexto histórico do pós-positivismo são o espelho da ideologia da sociedade e dos valores acolhidos na ordem jurídica". Entre normas-princípio poderá haver colisão, onde um direito fundamental não exclui o outro. Ocorre uma atividade de ponderação, e a partir da realização do princípio da proporcionalidade prevalece, no caso concreto, aquele que possui o maior peso.

No entanto, diferentemente ocorre com as regras jurídicas. Entre elas poderá ocorrer não a colisão, mas o conflito. Dessa forma, havendo conflito entre duas regras, aplicam-se os mandamentos de validade e apenas uma prevalecerá. Para Belchior (2011, p. 94, grifo do autor), "o próprio vocábulo conflito já dá a entender um choque, sendo impossível que duas regras coexistam. Somente uma será válida". 
O direito ambiental, como ciência autônoma, apesar de apresentar caráter interdisciplinar, obedece a princípios específicos de proteção ambiental. Dessa forma, os princípios caracterizadores do direito ambiental têm como "escopo fundamental orientar o desenvolvimento e a aplicação de políticas ambientais que servem como instrumento fundamental de proteção ao meio ambiente e, consequentemente, à vida humana" (GARCIA; THOMÉ, 2015, p. 17).

De acordo com Antunes (2015, p. 23) "os princípios jurídicos ambientais devem ser buscados, no caso do ordenamento jurídico brasileiro, em nossa Constituição e nos fundamentos éticos que iluminam as relações entre os seres humanos." Nesse sentido, Benjamin (apud MIRRA, 1996, p. 52) aponta as quatro principais funções dos princípios do direito ambiental no que diz respeito a sua compreensão, aplicação e alcance:

a) são os princípios que permitem compreender a autonomia do Direito Ambiental em face dos outros ramos do Direito; b) são os princípios que auxiliam no entendimento e na identificação da unidade e coerência existentes entre todas as normas jurídicas que compõem o sistema legislativo ambiental; c) é dos princípios que se extraem as diretrizes básicas que permitem compreender a forma pela qual a proteção do meio ambiente é vista na sociedade; d) e, finalmente, são os princípios que servem de critério básico e inafastável para a exata inteligência e interpretação de todas as normas que compõem o sistema jurídico ambiental, condição indispensável para a boa aplicação do Direito nessa área.

Nota-se, entretanto, que além de não existir um consenso sobre os princípios de direito ambiental, são enormes as divergências doutrinárias sobre a quantidade e denominação de cada um deles, em razão de que parte dos princípios ambientais são construções doutrinárias inferidas dos textos legais e das declarações internacionais de Direito. Desse modo, passa-se a apresentar de forma geral os mais importantes princípios ambientais tratados pela doutrina e pela jurisprudência brasileira.

a) Princípio de desenvolvimento sustentável

O conceito de 'desenvolvimento sustentável' foi definido pela Comissão Mundial sobre Meio Ambiente e Desenvolvimento da Organização das Nações Unidas ${ }^{1}$, em 1987, no relatório intitulado 'Nosso Futuro Comum' como "aquele que atende às necessidades do presente sem comprometer a possibilidade de as gerações futuras atenderem a suas próprias necessidades", ou seja, sem esgotar os recursos naturais ou degradar o ambiente, que o torna inadequado para a manutenção da vida.

Pode ser empregado, ainda, com o significado de "melhorar a qualidade de vida humana dentro dos limites da capacidade de suporte dos ecossistemas" (MILARÉ, 2014, p. 65). Para Sarlet e Fensterseifer (2012, p. 114) no conceito de desenvolvimento sustentável elaborado pela Comissão Brundtland, "verifica-se, de forma evidente, o forte conteúdo social de tal compreensão, na medida em que há uma preocupação em atender à necessidades vitais das gerações humanas presentes e futuras em sintonia com a eliminação da pobreza".

Outro marco importante acerca do desenvolvimento sustentável deu-se com a Declaração do Rio sobre Meio Ambiente e Desenvolvimento, proferida em 1992, também conhecida como ECO-92², ao sustentar no princípio 3ㅇ que o "direito ao desenvolvimento deve ser exercido de

\footnotetext{
${ }^{1}$ Comissão Mundial sobre o Meio Ambiente e Desenvolvimento. Nosso Futuro Comum. 2. ed. Rio de Janeiro: Fundação Getúlio Vargas, 1991 , p. 46. ${ }^{2}$ CONFERÊNCIA DAS NAÇÕES UNIDAS SOBRE DESENVOLVIMENTO SUSTENTÁVEL (Rio+20). Documentos de referência para a Rio+20. Disponível em: <http://www.onu.org.br/rio20/documentos/>. Acesso em: 04 jan. 2016.
} 
modo a permitir que sejam atendidas equitativamente as necessidades de desenvolvimento e de meio ambiente das gerações presentes e futuras".

No princípio 5o tem-se que "todos os Estados e todos os indivíduos, como requisito indispensável para o desenvolvimento sustentável, irão cooperar na tarefa essencial de erradicar a pobreza, a fim de reduzir as disparidades de padrões de vida e melhor atender às necessidades da maioria da população mundial".

No direito brasileiro, a Lei 6.938/81, que instituiu a Política Nacional do Meio Ambiente, contempla no seu art. 4으 $\mathrm{I}^{3}$ o princípio de desenvolvimento sustentável como um dos seus objetivos, ao estabelecer "a compatibilização do desenvolvimento econômico-social com a preservação da qualidade do meio ambiente e do equilíbrio ecológico".

Para Silva (2013, p. 27, grifo do autor), a conciliação dos dois valores consiste, assim, nos termos deste dispositivo, na promoção do chamado desenvolvimento sustentável, "que consiste na exploração equilibrada dos recursos naturais, nos limites da satisfação das necessidades e do bem estar da presente geração, assim como de sua conservação no interesse das gerações futuras".

Com a Constituição Federal de 1988 a sustentabilidade adquire fundamento constitucional, pois quando em seu art. $225^{4}$, impõe ao Poder Público e à coletividade o dever de defender e preservar o direito ao meio ambiente ecologicamente equilibrado 'para as presentes e futuras gerações" "está precisamente dando o conteúdo essencial da sustentabilidade" (SILVA, 2013, p. 28).

Machado (2014, p. 86) explica que a Constituição não utiliza a expressão 'desenvolvimento sustentável', mas a "inserção do dever de defender e preservar o meio ambiente para as presentes e futuras gerações representa a essência do princípio da sustentabilidade. Trata-se de um princípio implícito". Entende Amado (2015, p. 36) que:

É possível afirmar que implicitamente a Constituição Federal de 1988 recepcionou este principio no seu art. 225 e principalmente no art. 170. É que a Ordem Econômica, que se funda na valorização do trabalho humano e na livre iniciativa, tem como principio a Defesa do Meio Ambiente, inclusive mediante tratamento diferenciado conforme o impacto ambiental dos produtos e serviços e de seus processos de elaboração e prestação, não sendo exagero intitulá-la Ordem Econômica Ambiental.

Destaca-se também que o desenvolvimento sustentável é um princípio da ordem econômica, estando insculpido no artigo $170, \mathrm{VI}^{5}$ da Constituição Federal. Assim, para Fensterseifer (2008, p. 103) "toda prática econômica desajustada aos valores ambientais e sociais no seu processo produtivo estará agindo de forma contrária aos ditames constitucionais".

Afirma Fiorillo (2013, p. 79) que "a busca e a conquista de 'um ponto de equilíbrio' entre o desenvolvimento social, o crescimento econômico e a utilização dos recursos naturais exigem um adequado planejamento territorial que tenha em conta os limites da sustentabilidade". Milaré (2014, p. 72) destaca que no direito do ambiente, bem como na gestão ambiental, a sustentabilidade deve ser abordada sob vários prismas: "o econômico, o social, o cultural, o político, o tecnológico, o jurídico e outros".

\footnotetext{
${ }^{3}$ Art. 4ㅇ - A Política Nacional do Meio Ambiente visará:

I - à compatibilização do desenvolvimento econômico-social com a preservação da qualidade do meio ambiente e do equilíbrio ecológico;

${ }^{4}$ Art. 225. Todos têm direito ao meio ambiente ecologicamente equilibrado, bem de uso comum do povo e essencial à sadia qualidade de vida, impondo-se ao Poder Público e à coletividade o dever de defendê-lo e preservá-lo para as presentes e futuras gerações.

${ }^{5}$ Art. 170. A ordem econômica, fundada na valorização do trabalho humano e na livre iniciativa, tem por fim assegurar a todos existência digna, conforme os ditames da justiça social, observados os seguintes princípios:

$[\ldots]$

$\mathrm{VI}$ - defesa do meio ambiente, inclusive mediante tratamento diferenciado conforme o impacto ambiental dos produtos e serviços e de seus processos de elaboração e prestação.
} 
Verifica-se que o desenvolvimento sustentável "é um processo de mudança na qual o uso de recursos, as políticas econômicas, a dinâmica populacional e as estruturas institucionais estão em harmonia e reforçam o potencial atual e futuro para o progresso humano" (MILARÉ, 2014, p. 62). Portanto, "o desenvolvimento e a sustentabilidade não apenas são compatíveis, mas se constituem mutuamente" (FREITAS, 2011, p. 110).

Nesse sentido, com a crise ambiental, a sustentabilidade se apresenta como marco axiológico-constitucional. É um valor que nasce da realidade e que penetra em todos os ramos de conhecimento, inclusive nas ciências jurídicas, devendo a ordem jurídica ser relida no sentido de efetivá-lo. Dessa forma, o Estado de Direito Ambiental constitui-se de num paradigma viável, sendo possível sua realização perante o atual ordenamento jurídico constitucional.

b) Princípio da participação comunitária ou cidadã

O princípio de participação comunitária pressupõe a conduta de "tomar parte em alguma coisa, agir em conjunto" (FIORILLO, 2013, p. 126). Assim, dada a importância e a necessidade de uma ação conjunta, o legislador constituinte consagrou na Constituição Federal de 1988 que a defesa do meio ambiente deve ser imposta à coletividade e ao poder público. Sendo assim, referido princípio foi inserido no art. $225^{6}$, caput, da CF.

Dessa forma, o princípio em comento "decorre do direito de todos ao meio ambiente ecologicamente equilibrado e do regime jurídico do ambiente como bem de uso comum do povo, impondo a toda a sociedade o dever de atuar na sua defesa" (GARCIA; THOMÉ, 2015, p. 52). Oportuno considerar que não se trata de um aconselhamento, mas de um dever, um agir, imposto à coletividade na defesa e preservação do meio ambiente para as presentes e futuras gerações.

\section{c) Princípio da precaução}

O princípio da precaução foi proposto formalmente na Conferência do Rio 92, no princípio 15 da 'Declaração do Rio', da qual o Brasil foi signatário. Consta no princípio 15 que "com o fim de proteger o meio ambiente, os Estados deverão aplicar amplamente o critério da precaução de acordo com suas capacidades" (GARCIA; THOMÉ, 2015, p. 32). Trata-se da "dúvida científica. Trabalha com risco incerto, desconhecido ou abstrato" (AMADO, 2015, p. 34).

Nesse sentido, "na dúvida, opta-se pela solução que proteja imediatamente o ser humano e conserve o meio ambiente (in dubio por salute ou in dubio pro natura)" (MACHADO, 2014, p. 108). Em suma, o principio da precaução traz na sua essência uma verdadeira "ética do cuidado", que não se satisfaz apenas com a ausência de certeza dos malefícios, mas privilegia a conduta humana que menos agrida, ainda que eventualmente, o meio natural (GARCIA; THOMÉ, 2015, p. 32).

Pode se dizer, ainda, que o princípio aqui tratado está implícito na Constituição Federal, no inciso $V$ do artigo 225, onde o legislador se preocupou em "controlar a produção, a comercialização e o emprego de técnicas, métodos e substâncias que comportem risco para a vida, a qualidade de vida e o meio ambiente". Todavia, importa destacar que diante da incerteza dos possíveis efeitos negativos, por precaução, devem-se impor restrições ou impedir a intervenção até que se comprove que a atividade não acarreta efeitos adversos ao meio ambiente.

\section{d) Princípio da prevenção}

Aplica-se o princípio da prevenção "a impactos ambientais já conhecidos e dos quais se possa, com segurança, estabelecer um conjunto de nexos de causalidade que seja suficientemente para a identificação dos impactos futuros mais prováveis" (ANTUNES, 2015, p. 48). Com base no

\footnotetext{
${ }^{6}$ Art. 225. Todos têm direito ao meio ambiente ecologicamente equilibrado, bem de uso comum do povo e essencial à sadia qualidade de vida, impondo-se ao Poder Público e à coletividade o dever de defendê-lo e preservá-lo para as presentes e futuras gerações.
} 
artigo 225, parágrafo 1o, inciso $\mathrm{IV}^{7}$, da Constituição Federal, o estudo de impacto ambiental é exemplo típico do princípio preventivo.

Cuida-se, portanto, "de princípio da certeza científica. Trabalha com o risco certo, conhecido ou concreto" (AMADO, 2015, p. 33). Na prática esse princípio tem a finalidade de impedir a ocorrência de danos ao meio ambiente através de medidas e estudos prévios, realizados pelos interessados antes da implantação de empreendimentos e atividades efetiva ou potencialmente poluidoras, dentre outras medidas preventivas a serem exigidas pelos órgãos públicos.

\section{e) Princípio do poluidor-pagador}

O princípio do poluidor-pagador é considerado fundamental na política ambiental, sendo entendido como um "instrumento econômico que exige do poluidor, uma vez identificado, suportar as despesas de prevenção, reparação e repressão dos danos ambientais" (GARCIA; THOMÉ, 2015, p. 41). Para sua aplicação, os custos sociais externos que acompanham o processo de produção devem ser internalizados.

Referido princípio foi introduzido pela Organização para Cooperação e Desenvolvimento Econômico - OCDEA, mediante adoção, aos 26 de maio de 1972, da Recomendação C(72) 128, do Conselho Diretor, que trata de princípios dos aspectos econômicos das políticas ambientais (ANTUNES, 2015). A 'Declaração do Rio', de 1992, tratou da matéria em seu Princípio $16^{8}$. No Brasil, foi inserida na Lei 6.9381, no seu art. 4을 inciso $\mathrm{VII}^{9}$, bem como na Constituição Federal no art. 225, parágrafo $3^{0}{ }^{10}$ (MILARÉ, 2014).

f) Princípio da proibição do retrocesso ambiental

De acordo com o princípio da proibição do retrocesso ambiental, "deverá o legislador evoluir na edição de normas ambientais cada vez mais protetivas, não devendo, em regra, flexibilizar as normas ambientais, que seria um grande retrocesso" (AMADO, 2015, p. 43). Nesse sentido, Milaré (2014, p. 278, grifo do autor) destaca que:

A retroatividade, que aqui é proibida, na verdade, é aquela que deixa de proteger um direito fundamental já consolidado, que vem sendo conquistado e consolidado ao longo do tempo. Daí falar-se em não retroceder, no sentido de não recuar, não se desfazer de um direito já sabidamente fundamental, para dar lugar a outro, cujo valor (especialmente ao interesse difuso) é controverso.

Defende-se, portanto, que a proibição do retrocesso deve integrar o rol de princípios gerais do Direito Ambiental. Entretanto, caberá ao operador do Direito, para que referido principio se

\footnotetext{
${ }^{7}$ Art. 225. Todos têm direito ao meio ambiente ecologicamente equilibrado, bem de uso comum do povo e essencial à sadia qualidade de vida, impondo-se ao Poder Público e à coletividade o dever de defendê-lo e preservá-lo para as presentes e futuras gerações.

$\S 1$ 을 Para assegurar a efetividade desse direito, incumbe ao Poder Público:

$[\ldots]$

IV - exigir, na forma da lei, para instalação de obra ou atividade potencialmente causadora de significativa degradação do meio ambiente, estudo prévio de impacto ambiental, a que se dará publicidade.

${ }^{8}$ As autoridades nacionais devem procurar promover a internacionalização dos custos ambientais e o uso de instrumentos econômicos, tendo em vista a abordagem segundo a qual o poluidor deve, em princípio, arcar com o custo da poluição, com a devida atenção ao interesse público e sem provocar distorções no comércio e nos investimentos internacionais.

${ }^{9}$ Art. 4ㅇ - A Política Nacional do Meio Ambiente visará:

$[\ldots]$

VII - à imposição, ao poluidor e ao predador, da obrigação de recuperar e/ou indenizar os danos causados e, ao usuário, da contribuição pela utilização de recursos ambientais com fins econômicos.

${ }^{10}$ Art. 225. Todos têm direito ao meio ambiente ecologicamente equilibrado, bem de uso comum do povo e essencial à sadia qualidade de vida, impondo-se ao Poder Público e à coletividade o dever de defendê-lo e preservá-lo para as presentes e futuras gerações.

$[\ldots]$

§ 3 As condutas e atividades consideradas lesivas ao meio ambiente sujeitarão os infratores, pessoas físicas ou jurídicas, a sanções penais e administrativas, independentemente da obrigação de reparar os danos causados.
} 
fortaleça e seja respeitado, cuidar para que sua aplicação, quando em conflito, seja razoável e que mantenha seus objetivos, sempre no resguardado do direito constitucionalmente assegurado.

g) Princípio democrático

O princípio democrático "assegura ao cidadão a possibilidade de participar das políticas públicas ambientais" (SIRVINSKAS, 2014, p. 144). Essa participação poderá se dar em três esferas: legislativa, administrativa e processual. Para Antunes (2015, p. 27):

O princípio democrático assegura aos cidadãos o direito de, na forma da lei ou regulamento, participar das discussões para a elaboração das políticas públicas ambientais e de obter informações dos órgãos públicos sobre matéria referente à defesa do meio ambiente e de empreendimentos utilizadores de recursos ambientais e que tenham significativas repercussões sobre o ambiente, resguardando o sigilo industrial.

No sistema constitucional brasileiro é possível exercer a participação por várias formas diferentes. Assim, na esfera legislativa, o cidadão poderá diretamente exercer a soberania popular por meio do plebiscito (art. 14, I, da CF), referendo (art. 14, II, da CF) e iniciativa popular (art. 14, III, da CF). Na esfera administrativa, o cidadão pode utilizar-se do direito de informação (art. 5o, XXXIII, da CF), do direito de petição (art. 5ํ, XXXIV, da CF) e do estudo de impacto ambiental (art. 225, § 10, IV, da CF) (SIRVINSKAS, 2014).

Por fim, na esfera processual, o cidadão poderá também exercer a participação, utilizandose da ação civil pública (art. 129, III, da CF), da ação popular (art. 5ํ, LXXIII, da CF), do mandado de segurança coletivo (art. 5ำ, LXX, da CF), do mandado de injunção (art. 5ㅇ, LXXI, da CF), da ação civil de reponsabilidade por improbidade administrativa (art. 37, §4으, da CF) e da ação direta de inconstitucionalidade (art. 103 da CF) (SIRVINSKAS, 2014).

h) Princípio da responsabilidade

O princípio da responsabilidade estabelece que "qualquer violação do Direito implica na sanção do responsável pela quebra da ordem jurídica" (ANTUNES, 2015 p. 52). O artigo 225, § 3ㅇ, da Constituição Federal estabelece a responsabilidade por danos ao meio ambiente, embora não defina o caráter subjetivo ou objetivo dela. A legislação ordinária definiu pela responsabilidade objetiva no âmbito ambiental e a dividiu em: a) civil; b) administrativa; e c) penal (MILARÉ, 2014).

\section{CONCLUSÃO}

A abordagem entre regras e princípios é essencial para tratar da natureza dos direitos fundamentais. Dessa forma, verifica-se que a norma jurídica que trata do direito fundamental ao meio ambiente possui um conteúdo essencial oriundo de sua natureza principiológica, núcleo este que representa a própria justiça, essência do direito. Portanto, quando ocorrer diante de um caso concreto a colisão de um direito fundamental ao meio ambiente com outro direito fundamental, prevalecerá aquele que possuir o peso maior.

Sendo assim, para que o alcance almejado pela norma jurídica ambiental seja alcançado, ou seja, para que se concretize a efetiva proteção ambiental, é de suma importância que os princípios basilares que fundamentam o Direito Ambiental sejam respeitados, integralizados e harmonizados ao sistema jurídico vigente. Nesse sentido, será possível vislumbrar que o direito humano ao meio ambiente ecologicamente equilibrado será implementado e garantido para as pressentes e futuras gerações. 


\section{REFERÊNCIAS}

AMADO, F. Direito Ambiental. 3. ed. rev. e atual. Salvador: Juspodivm, 2015 (Coleção Resumos para Concursos, v. 16).

ANTUNES, P. de B. Direito ambiental. 17. ed. São Paulo: Atlas, 2015.

COELHO, L. F. Fumaça do bom direito: ensaios de filosofia e teoria do direito. Curitiba: Bonijuris, 2011.

FARIAS, T. Q. Princípios gerais do direito ambiental. Âmbito Jurídico, Rio Grande, v. 9, n. 35, dez., 2006. Disponível em: <http://www.ambito-

juridico.com.br/site/index.php?n_link=revista_artigos_leitura\&artigo_id=1543>. Acesso em: 01 agos. 2016.

FENSTERSEIFER, T. Direitos fundamentais e proteção do ambiente: A dimensão ecológica da dignidade humana no marco jurídico-constitucional do Estado Socioambiental de Direito. Porto Alegre: Livraria do Advogado, 2008.

FIORILLO, C. A. P. Curso de direito ambiental brasileiro. 14. ed. São Paulo: Saraiva, 2013.

FREITAS, J. Sustentabilidade: direito ao futuro. Belo Horizonte: Fórum, 2011.

GARCIA, L. de M.; THOMÉ, R. Direito Ambiental. Princípios; competências constitucionais. 8. ed. rev. e atual. Salvador: Juspodivm, 2015 (Coleção Leis Especiais para Concurso, v. 10).

MACHADO, P. A. L. Direito ambiental brasileiro. 22. ed. São Paulo: Malheiros, 2014.

MILARÉ, É. Direito do ambiente: a gestão ambiental em foco: doutrina, jurisprudência, glossário. 9. ed. São Paulo: Revista dos Tribunais, 2014.

MIRRA, A. L. V. Princípios fundamentais do direito ambiental. Revista de Direito Ambiental, São Paulo, n. 02, abr./jun., 1996. Disponível em:

<http://www.direitoambiental.adv.br/ambiental.qps/Ref/PAIA-6SRNQ8>. Acesso em: 01 agos. 2016.

SARLET, I. W.; FENSTERSEIFER, T. Direito ambiental constitucional: constituição, direitos fundamentais e proteção do ambiente. 2. ed. São Paulo: Revista dos Tribunais, 2012.

SILVA, J. A. da. Direito ambiental constitucional. 10. ed. São Paulo: Malheiros, 2013.

SIRVINSKAS, L. P.. Manual de direito ambiental. 12. ed. São Paulo: Saraiva, 2014.

TEIXEIRA, O. P. B. O direito ao meio ambiente ecologicamente equilibrado como direito fundamental. Porto Alegre: Livraria do Advogado, 2006. 